\title{
A MARC II-BASED PROGRAM FOR RETRIEVAL AND DISSEMINATION
}

Georg R. MAUERHOFF: Head, Tape Services, National Science Library and Richard G. SMITH: Analyst/Programmer, Research and Planning Branch, National Library, Ottawa, Canada (Formerly with Library and Computation Center, University of Saskatchewan)

Subscriptions to the Library of Congress' MARC tapes number approximately sixty. The uses to which the weekly tapes have been put have been minimal in the area of Selective Dissemination of Information (SDI) and current awareness. This paper reviews work that has been performed on batched retrieval/dissemination and provides a description of a highly flexible cooperative SDI system developed by the Library, University of Saskatchewan, and the National Science Library. The system will permit searching over all subject areas represented by the English language monographic literature on MARC.

\section{INTRODUCTION}

With subscriptions to the Library of Congress' MARC II tapes numbering approximately sixty (1), the utilization of standardized bibliographic information in machine readable form has reached an all-time high. Numerous subscribers have written programs to access the tapes in order to produce acquisitions and cataloging products, but, unfortunately, the search techniques in these programs have been limited to searching of fixed-length information, such as LC card numbers, Standard Book Numbers (SBN's) and compression codes. Accelerated developments of searching mechanisms have been made by those involved with on-line bibliographic systems, but work on MARC information retrieval in the batch mode has 
been evolving very slowly. That is, the proffering of an assortment of remedies for one of the oldest library problems, that of current awareness and Selective Dissemination of Information (SDI) using MARC, has not received the emphasis it should.

The Library of the University of Saskatchewan has been utilizing the MARC tapes since their weekly distribution on 1 April 1969, with areas of usefulness so far having been restricted by the kinds of searching methods available. Concern has therefore been shown for a far greater exploitation of the MARC records. Since no algorithms other than time decay have been established locally for limiting the size of the file to items which have a high degree of usefulness, and since the cost of updating and storing the weekly files has to be incurred, it is only fitting that as many bibliographic records as possible be monitored and disseminated to those sections of the University where they can be most effectively used. A program package for current awareness/SDI is the most likely method for achieving this.

Collaborative efforts are now the only realistic means of exploiting MARC. Costs can be spread over a large user group, and at the same time personalized services are assured to those taking part. It is for this reason that the Office of Technical Services (OTS), Library, University of Saskatchewan, has been cooperating with the National Science Library (NSL), National Research Council of Canada, on the development of such a current awareness/dissemination system. Known by the acronym SELDOM (Selective Dissemination of MARC), the program represents cooperation in the true sense of the word, in that the OTS's experiences with MARC are being coupled with NSL's expertise in nation-wide SDI.

This paper will describe in detail the evolution of SELDOM, with a future paper to document user reaction to the SELDOM program.

\section{HISTORY}

The University of Saskatchewan is not alone in the investigation of MARC-based retrieval/dissemination programs. The Oklahoma Department of Libraries, under the coordination of $\mathrm{K}$. J. Bierman $(2,3,4,5)$, has been operating a weekly MARC SDI service since February of 1970 and found its reception overwhelming. Over twenty user groups in the United States and Canada are presently experimenting with this current awareness service in various subject fields, using the Dewey Decimal and the Library of Congress classification numbers as search keys. Oklahoma's efforts followed the study by William J. Studer (6) and the Aerospace Research Applications Center (ARAC) at Indiana University. Studer's hypothesis was "that an SDI system concerned with book-type material would be of significant benefit to faculty in keeping them alerted to what is being published in their fields of interest-especially faculty in the non-technical areas where books are probably still as vital, if not more important, a medium of information and ideas as periodical and report literature (7)". 
In his experiment, Studer translated participants' interests into profiles consisting of weighted Library of Congress subject headings and classification numbers.

Henriette Avram (8) of the Library of Congress' MARC Development Office reported on information retrieval using the MARC Retriever, a modification of Programmatics Inc.'s system known as AEGIS. Regarded as "essentially a research tool that should be implemented as inexpensively as possible," the MARC Retriever is tape based and able to accept almost any kind of bibliographic query. Unfortunately, it is only operational at the Library of Congress. Along similar lines are Syracuse University's L.C. MARC on MOLDS and LEEP projects $(9,10,11,12)$. The interactive retrieval capabilities, which are used in both batch and on-line modes, permit a variety of queries over their MARC data bases.

Additional projects reporting on the subject approach to MARC tapes in a batch environment are not numerous. Dohn Martin (13) at the Washington University School of Medicine describes a searching method by L.C. classification numbers, in which a PL/I program is used to produce selection lists for the medical library. This is along the same lines as the work reported by J. G. Veenstra (14) of the University of Florida, D. L. Weisbrod (15) of the Yale University Library, and F. M. Palmer (16) of Harvard University Library. In Sweden, Bjorn Tell (17) has run a MARC II test tape in his integrated information retrieval system called ABACUS, while in Edmonton, Canada, Doreen Heaps (18) reports on author and title searches of MARC tapes in a Chemical Titles format. In England, related research is being contemplated by F. H. Ayres (19) for BNB MARC tapes. In Ireland (20), also, plans are in the offing for SDI services based on BNB MARC tapes, while in the United States, the first commercial venture is underway by Richard Abel and Company (21), which is contemplating selective dissemination of announcements.

\section{BACKGROUND}

The National Science Library has been providing an SDI service for Canada's Scientific and Technical Information (STI) community since April, 1969, spinning a variety of machine readable indexing and abstracting services on a regular basis. A questionnaire (22) was sent out by CAN/SDI Project officials in May 1970, asking its subscribership to suggest where subject expansion should take place in the future. Although the responses emphasized the life sciences, e.g. Biological Abstracts' BA Previews and Medlars, the NSL was nevertheless quite enthusiastic about adding the Library of Congress' MARC II tapes to their present SDI service, especially if the project programming could be accomplished elsewhere. Twenty-one subscribers responded to the MARC II tapes, indicating the existence of a good user group, although not one of top priority. The University of Saskatchewan Library expressed a willingness to perform the systems work and project programming, which was estimated to require less than four 
man-months, making SELDOM operational by February 1971.

\section{THE SELDOM PROGRAM}

\section{Facilities and Programming Languages}

In order for the OTS to make use of the PL/I and Assembler programs, an IBM S360 computer configuration consisting of at least 100K memory and a PL/I compiler was deemed necessary. This presented no problem because the Library had at its disposal an IBM S360/50 with $256 \mathrm{~K}$ bytes of memory.

Additional hardware specifications include four tape drives, a 2314 disk and two 1403 printers, one with a TN option. The latter is soon to be replaced with the ALA approved library print train.

Now, however, because of the addition of Large Core Storage (LCS), large bibliographic files such as MARC will be processed much more easily. Release 19 of OS MFT was also implemented in order to effectively utilize this additional million bytes of LCS memory. This more than modest memory has great utility, although serious investigations of automated library systems such as this one can take place even with small memories.

As can be imagined, the switchover to Release 19 came at an inopportune time as far as the SELDOM programs were concerned. Implementation of the new release affected the scheduling and turn-around times.

\section{The SELDOM Record Format}

Several years ago, the National Science Library decided to adopt a standard MARC II-like format and design programs to convert suppliers' tapes to this standard format. When a decision is made to add a new tape service, such as Biological Abstracts' BA-Previews, to the present inventory of CAN/SDI tapes, the NSL personnel select those bibliographic items which will find use in an SDI environment. Selected items are then pulled from the input tape by the conversion program, and structured into an NSL format. This then was the first of many tasks facing the OTSdetermining which fields should be utilized from the LC MARC tape for searching and printing.

Of approximately fifty MARC tags, fixed and variable, only 32 contain information that might be of interest to users of the system for searching. These tags, however, can be grouped into analytical units, i.e. units of like information. Arranged in six term types, they are: personal name, corporate name, classification, title, geographic area code, and date. The abbreviations for the term types are P, B, K, T, G, and D respectively. Users then will be able to request information from the system in many ways, whether it be for a title term, or a combination of categories such as classification number and geographic area code. The twenty-three fields and five subfields chosen, along with their respective analytics are shown in Table 1, where [ ] are not searched and ${ }^{\circ}$ are OTS calculations. Percentages of occurrence, which was the criterion used for selection of the 
tags, are also indicated in the table. All the 500 tags were omitted because NSL and the OTS do not wish to search abstracts, annotations, or bibliographic notes at this time. Where frequencies were not available from the Library of Congress' publication entitled Format Recognition Process for MARC Records: a Logical Design, the OTS conducted its own counts over a tape selected at random. The tape chosen (Volume 2, Number 23) for the counts contained 881 records.

\section{Table 1. Search Field Definitions}

\begin{tabular}{|c|c|c|}
\hline \multicolumn{3}{|r|}{$\%$ of Occurrence } \\
\hline \multirow{5}{*}{$\begin{array}{l}\text { Search Key } \\
\text { Personal Name (P) }\end{array}$} & Field/Subfield & Per Record \\
\hline & $\begin{array}{c}100 \\
{[400]}\end{array}$ & 84.7 \\
\hline & {$\left[\begin{array}{l}{[400]} \\
600\end{array}\right.$} & $<0.1$ \\
\hline & 700 & 22.4 \\
\hline & [800] & 0 \\
\hline \multirow{6}{*}{ Corporate Name (B) } & 110 & 11.7 \\
\hline & $260 \$ B$ & 97.9 \\
\hline & $410 \$ \mathrm{~A}$ & 2.4 \\
\hline & 610 & 4.8 \\
\hline & 710 & 11.1 \\
\hline & $810 \$ \mathrm{~A}$ & 4.6 \\
\hline \multirow[t]{18}{*}{ Title $(\mathrm{T})$} & 111 & 1.5 \\
\hline & 130 & 0.2 \\
\hline & 240 & $4.3^{\circ}$ \\
\hline & [241] & $0.1^{\circ}$ \\
\hline & 245 & 100.0 \\
\hline & $410 \$ \mathrm{~T}$ & 2.4 \\
\hline & [411] & $<0.1$ \\
\hline & 440 & 6.0 \\
\hline & [611] & 0.1 \\
\hline & 630 & 0.9 \\
\hline & 650 & 95.9 \\
\hline & 651 & 17.5 \\
\hline & 711 & 0.2 \\
\hline & 730 & 0.8 \\
\hline & 740 & $4.1^{\circ}$ \\
\hline & $810 \$ \mathrm{~T}$ & 4.6 \\
\hline & [811] & 0.1 \\
\hline & 840 & 0.5 \\
\hline \multirow[t]{3}{*}{ Classification (K) } & 050 & 105.1 \\
\hline & 051 & $0.9^{\circ}$ \\
\hline & 082 & 95.8 \\
\hline Geographic Code (G) & 043 & $34.0^{\circ}$ \\
\hline Date (D) & 009 (i.e. 008) & 100.0 \\
\hline
\end{tabular}


The fact that only 28 data elements were chosen for searching purposes proved highly useful, since the National Science Library's search module was designed, for the sake of efficiency, to accommodate a maximum of 32 search field definitions. The program can handle this many fields, but on the average it makes use of approximately twelve fields per record. There may be occasions, however, when as few as seven or as many as twenty-two directory entries will be handled, not counting subfields. Table 2 is a distribution of directory entries for the sample MARC II file tape. The mean of the distribution of entries is 13 , and the median 12 .

\begin{tabular}{|c|c|c|}
\hline $\begin{array}{l}\text { \# of dir. entries } \\
\leq \leq 6\end{array}$ & \# Records & $\%$ \\
\hline $\begin{array}{r}\leq 6 \\
7\end{array}$ & $\begin{array}{l}0 \\
2\end{array}$ & $\begin{array}{l}0 \\
.23\end{array}$ \\
\hline 8 & 0 & 0 \\
\hline 9 & 28 & 3.18 \\
\hline 10 & 74 & 8.40 \\
\hline 11 & 116 & 13.17 \\
\hline 12 & 160 & 18.16 \\
\hline 13 & 149 & 16.91 \\
\hline 14 & 123 & 13.96 \\
\hline 15 & 106 & 12.03 \\
\hline 16 & 69 & 7.83 \\
\hline 17 & 25 & 2.84 \\
\hline 18 & 19 & 2.16 \\
\hline 19 & 5 & .57 \\
\hline 20 & 3 & .34 \\
\hline 21 & 1 & .11 \\
\hline 22 & 1 & .11 \\
\hline \multirow{2}{*}{$\geq 23$} & 0 & 0 \\
\hline & 881 & 100. \\
\hline
\end{tabular}

At the same time that decisions were being made regarding the inclusion of certain search fields, print field definitions were structured. Although the programs can accommodate any number of directory items, only 31 are required for satisfactory and meaningful output. The analytics for these definitions make up Table 3 , where ${ }^{\circ}$ are OTS calculations. Frequency statistics are again included.

Description of Programs

The SELDOM software is comprised of four modules. These modules (A, B, C, D) are easily identified in the system flowchart (Figure 1) and are: "A" the translation and conversion of MARC; "B" the searching of files; "C" the outputting of the search results, and " $\mathrm{D}$ " the compiling of profiles. Two IBM utility programs are also used. 
Table 3. Print Field Definitions

$\begin{array}{lr}\text { Term(s) Causing Retrieval } & \text { \% of Occurrence Per Record } \\ \text { Main Entry } & - \\ \text { Title Statement } & 98.6 \\ \text { Edition Statement } & 100.0 \\ \text { Imprint } & 4.1 \\ \text { Collation Statement } & 100.0 \\ \text { Series Statement/Notes } & 100.0 \\ \text { Bibliographic Price } & 13.6 \\ \text { Subject Added Entries } & 39.7^{\circ} \\ \text { LC Card Number } & 131.6 \\ \text { Profile Number } & 100.0 \\ \text { Expression Number } & - \\ \text { Threshold Weight } & - \\ \text { Weight } & - \\ \text { Source } & - \\ \text { Form of Content } & - \\ \text { Language } & 53.2^{\circ} \\ \text { LC Class Number } & 100.0^{\circ} \\ \text { Dewey Decimal Number } & 105.1^{\circ} \\ \text { ISBN } & 95.8^{*} \\ \end{array}$

Translation and Conversion Program (LCONV)

The conversion program, called LCONV, converts the weekly MARC tape into a SELDOM MARC II-like format tape. The input records see the following changes: "\%" used as field terminator, " $\$$ " used as subfield delimiter, “@” used as record terminator, upper- and lower-case ASCII translated to upper case EBCDIC, diacritics removed, text compressed, and unromanized characters that can't be approximated removed.

The program is driven by two tables, one of which consists of the MARC tags in which the OTS is interested, and the other, the processes to which the selected tags will be subjected. Currently, all tags can be handled by one of four processes:

1) Process 1 extracts the language and the form of content code from MARC tag 008, and creates a new field 008 consisting of only these two units. Instead of a one-character code for form of content, a four-letter abbreviation delimited by " $\$ \mathrm{~A}$ " is used. Language of publication is delimited by " $\$ \mathrm{~B}$ ". Process 1 also extracts the first publication date from the original tag 008 , and sets up a new field, tagged 009 and delimited " $\$ A$ ".

2) Process 2 handles the Library of Congress (051, 052) and Dewey Decimal Classification (082). It utilizes only the first subfield, compresses out slashes, and limits the length of these fields to 20 characters.

3 ) The geographic area code (043) and imprint (260) are routed through a third process which retains the MARC subfield delimiters. Subfield delimiters are retained to narrow the object field and reduce search time. 
148 Journal of Library Automation Vol. 4/3 September, 1971

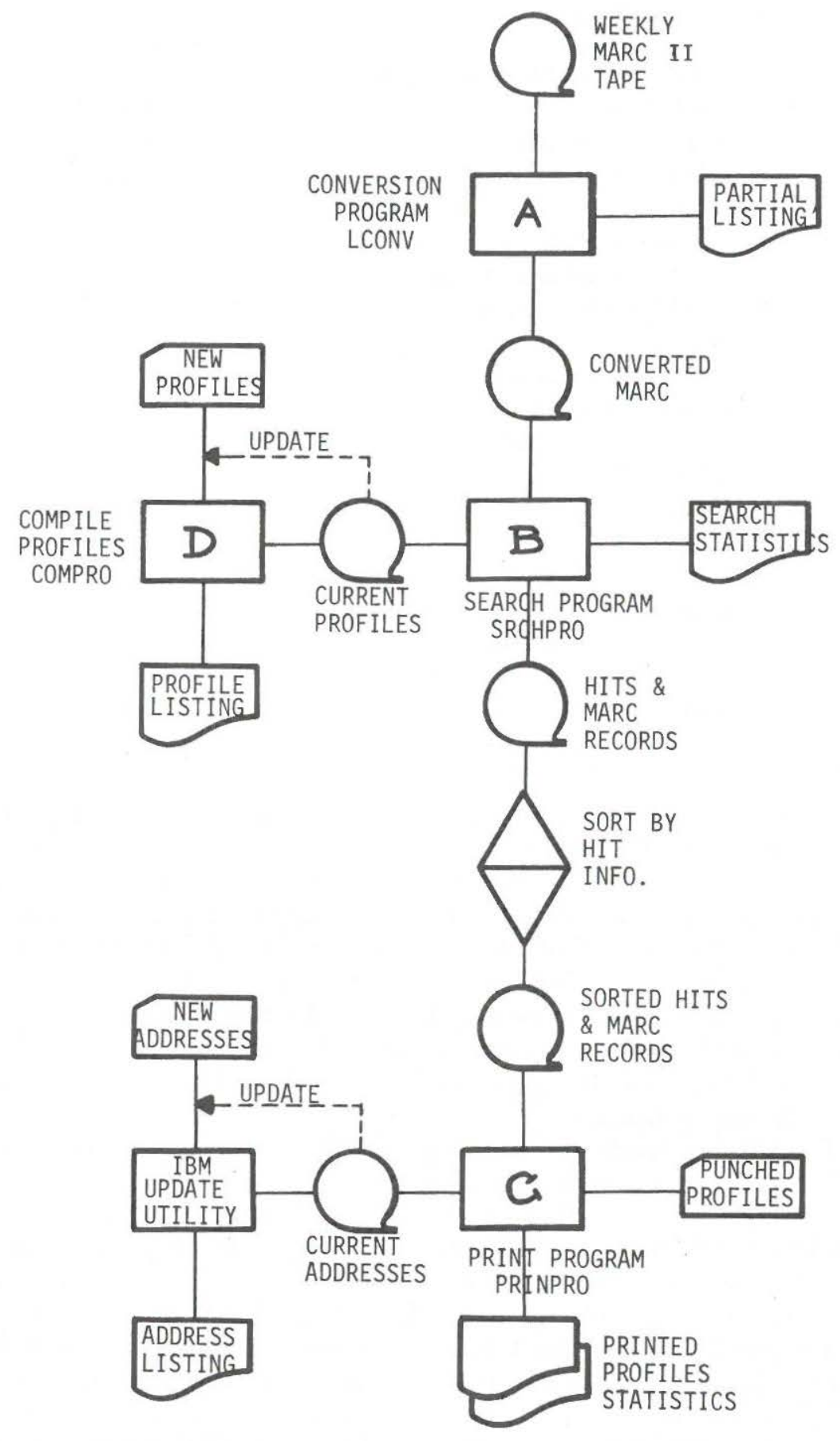

Fig. 1. System Flowchart of SELDOM. 
4) All other tags are routed through process 4, which removes subfield delimiters and heads up the entire field with " $\$ A$ ". Narrowing down the object field is not desirable for fields input to this process.

The conversion program also outputs for each record a field identified by 035 , a MARC II tag for local system number. This field contains data base code ( $\mathrm{R}$ for MARC), volume and issue number (extracted from MARC tape label), and the Library of Congress card number truncated to the first eight characters.

LCONV sorts the tags, calculates base address and record length, builds a new directory, and writes the SELDOM MARC II-like record out on tape.

\section{The Searching Program (SRCHPRO)}

The searching program accepts as input compiled profiles, the converted MARC tape from LCONV, and parameter cards specifying data base and up to 32 search field definitions. Each field definition consists of a term type code, tag, and delimiter of the field or subfield to be searched. Six term types are allowed, although additions, deletions and changes to these six may be performed upon requests. All terms except date may be truncated on the right, with title terms benefitting from left truncation. The right truncation feature reduces storage and search time requirements.

The searches are conducted over the converted tape according to the Boolean expressions which connect symbols representing profile words. Profile words are simply entered into core until the alloted core is filled, and the source tape is sequentially passed against the profiles; i.e., each of the records on the tape precipitates a search of the profile words in core. If all of the profile words were not entered into core, the source tape is rewound and another search is conducted. This continues until all profiles have been searched. An output tape is created containing the SELDOM record retrieved with a prefix consisting of the profile number, threshold weight, weight, expression number, hit number, and terms which caused retrieval of the record.

Users also have the option of applying a weight $(-99$ to +99$)$ to each profile word. Each time profile words match terms in a record, the weight value of each of the words found is tallied. Upon completing the search of that record and upon satisfying the expression logic, the total of the weight values is compared to a threshold value. Thus, if the total is greater than or equal to the threshold value $(-999$ to +999$)$, that particular record is retrieved.

Another option available to the user is a hit option, in which the user may specify the maximum number of records he would like various expressions in the program to retrieve for him.

\section{The Output Programs}

The output from the search program is sorted by calling up the IBM Sort Utility, which sorts the records on prefix. The sorted output is then 
input to the print program along with the address file. The latter is a separate file that is merely updated using the IBM Utility IEBUPDTE. It is in this address file, however, that several options can be specified. Duplicate printouts can be obtained, such that the left and right sides of the page carry identical output, with the right side carrying a feedback mechanism. Two-up printouts, notes, and if necessary, punched card output can be requested.

On the whole, the record printed out (see Figure 2) is similar in format to a $3 \times 5$ catalog card, the only differences being the fixed format, term or terms causing retrieval, the lack of name added entries and notes, and the control information at the bottom of each printout.

\section{PROFILE COMPILATION}

Because of the Library's bibliographic responsibility to the University, an alerting service such as SELDOM will vastly improve user awareness of the published monographic resources. First, users, in house and out, would not only be alerted to many works to be acquired by the Library, but would also be alerted to items that are currently not being purchased. Secondly, they would be assured of personalized services. Users of SELDOM will not receive listings of just new books, but will be notified of the latest books which are presumed to be relevant to their interests.

\section{Profiling}

When a prospective user (group) wishes to search a weekly MARC tape, his (its) interests are entered onto profile formulation sheets. These sheets (see Figures 3 and 4 ) contain a description of the user's subject interests, several references to the monographic literature, and a listing of the profile words with logical connectives. The profile words may number as many as 500 . Figure 5 shows three of the approximately eighty profiles currently running under SELDOM.

The profiles are formulated by search editors using words that appear in the user's narrative and references. Additional words are sought in the Library of Congress' List of Subject Headings. Classification numbers that express the appropriate areas are incorporated; depending upon the information need, personal names, corporate names, geographic area codes, and date are also prescribed.

According to Mauerhoff (23), approximately twenty-seven hours per year are required of an information specialist/search editor in order to accurately capture and maintain a user's need for information. This figure incorporates interviewing time, user education, analyses of user feedback, and revision time. The success of this system or of any information retrieval system therefore depends on having sufficient profiling staff.

\section{The Compile Program (COMPRO)}

COMPRO, compiling of profiles program, edits the profile transactions 


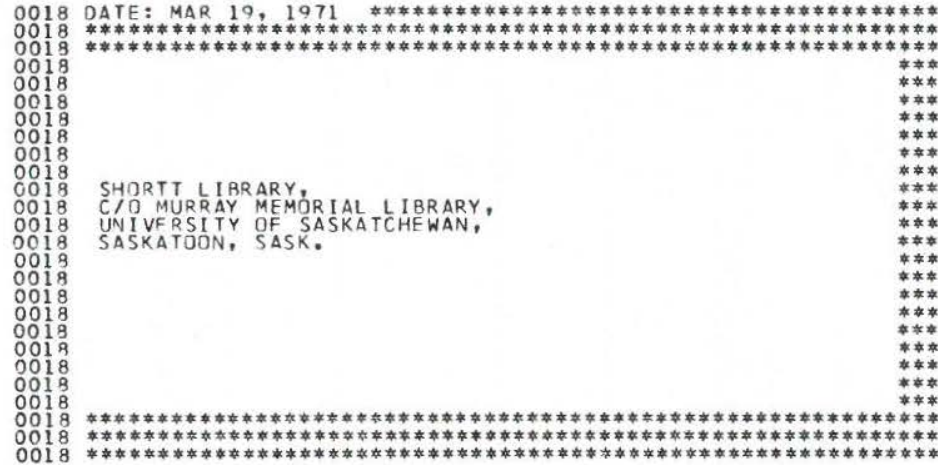

N CN AB, N CN BC

IRISH, ERNEST JAMES WINGETT, 1912 -

STRUCTURE OF THE NORTHERN FOOTHILLS AND EASTFRN MOUNTA IN, RAN
GEST, ALBERTA ANO BRITISH COLUMBIA, BETWEEN LATITUDES 53 I5, AN
O 57 . 201 , BY E. J. W. IRISH. <OTTAWA>DEPT. OF ENERGY, MINES AND RESOURCES $<1968$ >

38 P. ILLUS. FOLD. COL. MAPS (IN POCKET) 25 CM. *\#GEOLOGICA
SURVEY OF CANADA. BULLET IN 168 \# \#CANADA. GEOLOGICAL SURVEY. GEOLOGY BRITISH COLUMBIA. *\#GEOLOGY ALBERTA.

LC $77-524868$ P0018 EN 01 TW 000 WT 000 S R0249 FC LENG
QE 185

0018 *t.

O 18 *

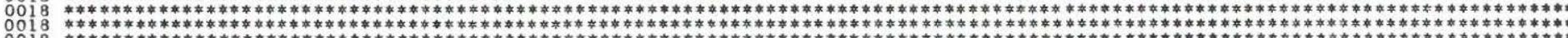

Fig. 2. Sample Profile Notices.
DATE: MAR 19, 1971

SELDOM PROJECT: MARC II VOL O2 NO 491971

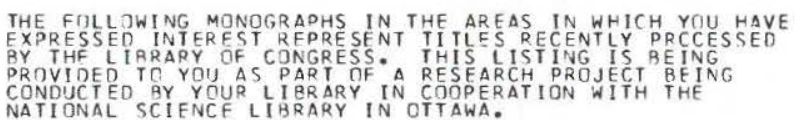

N CN NT

CUNDY, ROBERT.

BEACON SIX.

LONDON,EYRF \& SPOTTISWDODE, 1970.

253 P., 16 PLATES. ILLUS., ? MAPS, PORTS. $23 \mathrm{cN}$. $\$ 501-$

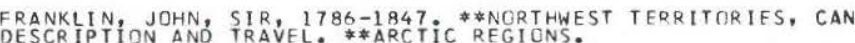

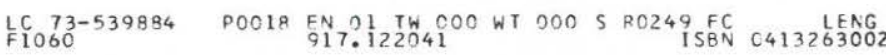

MURRAY MEMORIAL, LIBRARY, UNIVERSITY OF SASKATCHEMAN,
SASKATOON, SASK. 


\begin{tabular}{|c|}
\hline PROFILE - NUMBER \\
\hline 0003 \\
\begin{tabular}{|c|}
\hline SHEET - NUMBER \\
\hline 1
\end{tabular} \\
Reference Department \\
Murray Memorial Library \\
University of Saskatchewan \\
Saskatoon, Canada. \\
\hline
\end{tabular}

STATE YOUR SEARCH REQUEST IN NARRATIVE RORU AOO TWO REFERENCES OF PAPERS PUBLISHEO BY YOU OR A COLLEAGUE WORKING IN YOUR FIEZO (PLEASE TYPE QR PRINI)

This profile is intended to obtain information on current monographs that would most likely be of interest to the Reference Department, in order to keep the collection up to date. Reference works such as dictionaries, encyclopedias, handbooks, catalogues, etc. are the kinds of items sought.

References:

1. United Nations. Economic Commission for Europe. Sub-Committee on Urban Renewal and Planning. "Directory of National Bodies Concerned with Urban and Regional Research." New York: Unitec Nations, 1968. 134 pp. (JX1977)

2. Berlin, Roisman \& Kessler. "Law and Taxation; a Guide for Conservation and Other Nonprofit Organizations". Washington: Conservation Foundation, 1970. 47 pp. (KF6449)

3. Hayes, Robert M., and Becker, Joseph. "Handbook of Data Processing for Libraries." New York; Wiley-Interscience, 1970. 885 p.

4. Havlice, Patricia Pate. "Art in time". Metuchen, N.J.: Scarecrow Press, 1970. 350 p. (N7225; 016.7; Art -- Indexes) 


\begin{tabular}{|c|c|c|c|c|c|c|c|}
\hline $7 \pi$ & $w$ & $A C$ & PROFILE WORDS & $\pi$ & $w$ & $A C$ & PROFILE WOROS \\
\hline I & & $\bar{A}$ & ATLAS* & & & & \\
\hline II & & $B$ & ANNUAL & & & & \\
\hline TI & & $\mathrm{c}$ & ANNUALS & & & & \\
\hline TI & & $D$ & BIBL IOGRAPH* & & & & \\
\hline 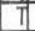 & & $\mathrm{E}$ & ALMANAC* & & & & \\
\hline & & $F$ & DICTIONAR* & & & & \\
\hline$T$ & & G & DIRECTORY & & & & \\
\hline T) & & $\mathrm{H}$ & DIRECTORIES & & & & \\
\hline \begin{tabular}{|l|l} 
T \\
\end{tabular} & & $\mathrm{I}$ & ENCYCLOPED* & & & & \\
\hline \begin{tabular}{|l|}
$T$ \\
\end{tabular} & & $\mathrm{~J}$ & FACTS & & & & \\
\hline 11 & & K & GLOSSAR* $^{*}$ & & & & \\
\hline \begin{tabular}{|l|}
$T$ \\
\end{tabular} & & $\mathrm{~L}$ & GUIDE* & & & & \\
\hline \begin{tabular}{|c|}
$T$ \\
\end{tabular} & & $M$ & HANDBOOK* & & & & \\
\hline T & & $\mathrm{N}$ & INDEX* & & & & \\
\hline T & & 0 & INTERL IBRARY & & & & \\
\hline \begin{tabular}{|l|}
$T$ \\
\end{tabular} & & $\mathrm{p}$ & CHECKLIST* & & & & \\
\hline T & & 0 & GENEALOGY & & & & \\
\hline \begin{tabular}{|c|}
$T$ \\
\end{tabular} & & $\mathrm{R}$ & MANUAL & & & & \\
\hline T & & S & MANUALS & & & & \\
\hline $\mathrm{T}$ & & $T$ & OUITL INF* * & & & & \\
\hline T & & U & REFERENCE & & & & \\
\hline \begin{tabular}{|l|l}
$T$ \\
\end{tabular} & & V & REPRINT* & & & & \\
\hline$T$ & & W & REVIEW $^{\star}$ & & & & \\
\hline T & & $x$ & SYLLABUS & & & & \\
\hline T & & $\bar{Y}$ & SYLLABI & & & & \\
\hline \begin{tabular}{|l}
$\mathrm{T}$ \\
\end{tabular} & & Z & CATALOG* ${ }^{\star}$ & & & & \\
\hline \begin{tabular}{|l|}
$T$ \\
\end{tabular} & & $\overline{A A}$ & ABSTRACT $^{*}$ & & & & \\
\hline \begin{tabular}{|l|}
$T$ \\
\end{tabular} & & $\overline{A B}$ & STATISTIC* & & & & \\
\hline T & & $A C$ & YEARBOOK* & & & & \\
\hline$T$ & & $A D$ & TEXTBOOK* & & & & \\
\hline & & & & & & & \\
\hline & & & & & & & \\
\hline & & & & & & & \\
\hline & & & & & & & \\
\hline & & & & & & & \\
\hline & & & & & & & \\
\hline & & & & & & & \\
\hline & & & & & & & \\
\hline
\end{tabular}

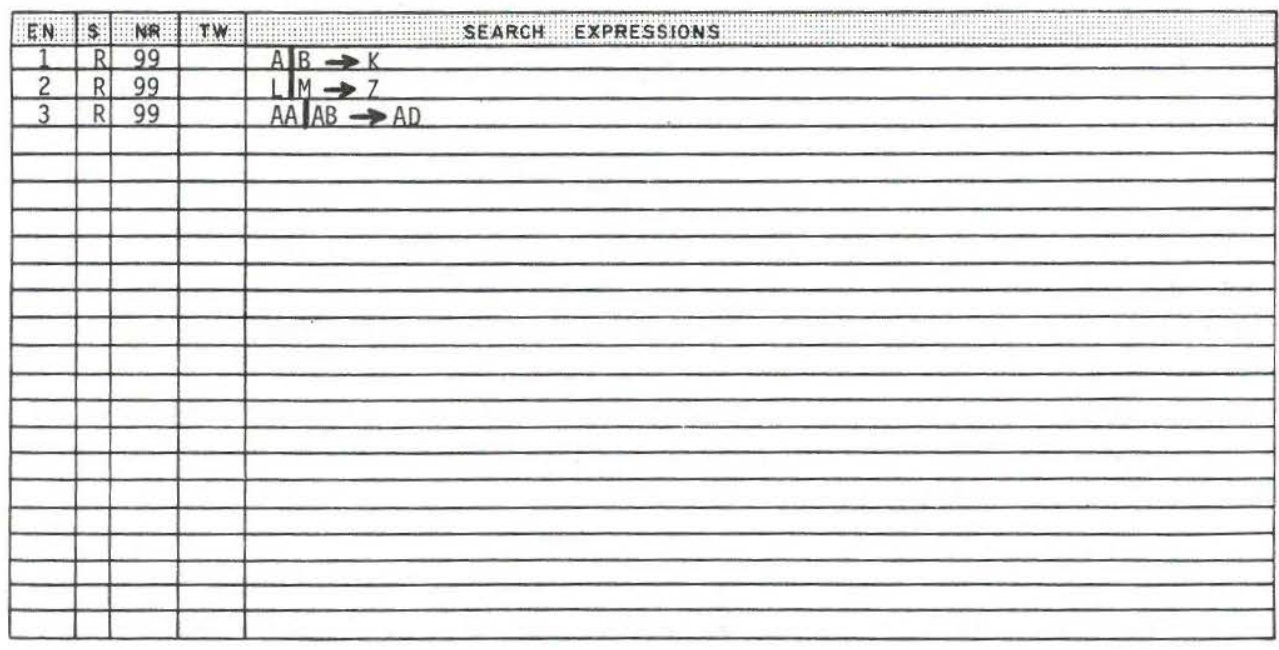

Fig. 4. Sample Profile Formulation Sheet: Terms and Logic. 


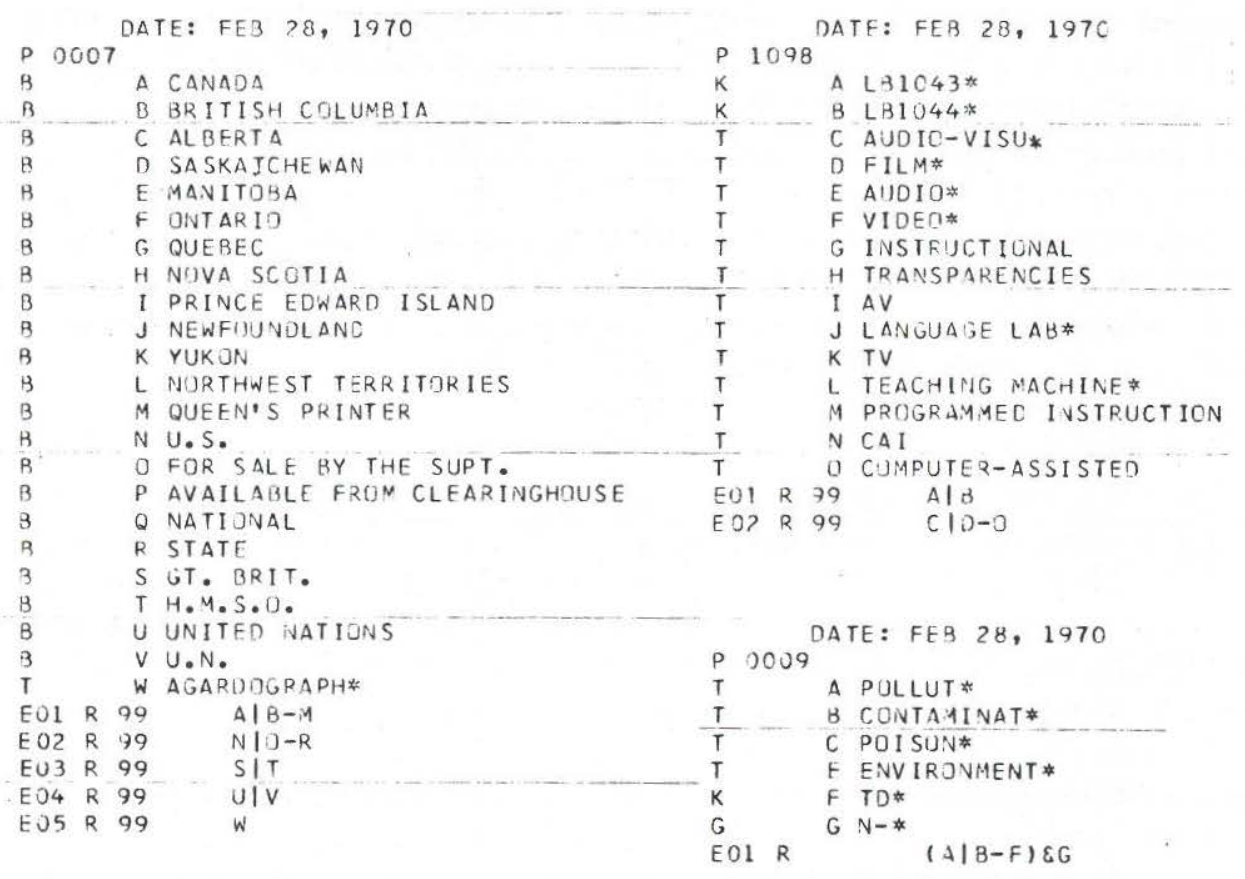

Fig. 5. Computer Version of Profiles.

for sequence, syntax and semantics, and generates codes for the Boolean operators in the search expressions. The program flags incorrect data base specifications, incorrect term types, and incorrect alpha codes (i.e. symbols corresponding to the profile words). Profile transactions are by way of card input, and can consist of profile additions, profile updates, and profile deletes. Listings accompany all transactions.

\section{OPERATION AND COSTS OF SELDOM}

From the time that SELDOM became operable on a day-to-day basis, cost information has been gathered, and since SELDOM is composed of four modules, the recording of items of cost has been easily done. For example, LCONV computer charges are presently $\$ 0.019$ per record converted based on weekly files ranging in size from 1194 records to 2399. This breaks down to about 1939 records per week, and averages out to about $\$ 37$ per MARC tape.

Following the preparation of the tape for searching, the SRCHPRO-Sort routine is run. The average computer cost has been about $\$ 0.186$ per profile per issue. SELDOM's user group presently numbers 81 , with profile terms numbering 1121 or 14 terms per profile, and questions or expressions numbering 273 or about 4 per profile.

PRINPRO was formerly running under stream-oriented transmission, at a total computer cost of $\$ 1.70$ per 1000 lines of output. A shift to record- 
oriented transmission has lowered charges to $\$ 1.50$ per 1000 lines. With profiles having averaged about 832 lines of output, the total cost of printing out search results has been about $\$ 1.25$ per profile.

Overall costs for the 81 profiles are presently about $\$ 2.23$ per profile per tape, or $\$ 116.00$ per profile per year. Since the profiles require updating at frequent intervals, charges of $\$ 0.37$ per profile per tape have been incorporated into this charge to take care of changes in terms and addresses. Costs which have not been included in the calculations are such items as MARC tape subscriptions, forms, and staff time.

\section{DISCUSSION}

The OTS and the NSL have at their disposal a program package that is highly flexible. For instance, search keys can be added or deleted at will. Fields from the MARC tapes can either be incorporated or removed from the directory. Any number of fields and subfields can be searched on tape, and any new directory items may be created, with the SRCHPRO limit, however, being 32 . This number was chosen because it satisfies $99 \%$ of the users' needs. Almost every procedure in the program is table driven, the result being that variations can easily be introduced into the programs. In consequence, if and when BNB MARC tapes are made available, and if and when a Canadian MARC service becomes a reality, searching of these tapes would present no problems whatsoever.

The benefits to be derived from SELDOM go beyond the concept of SDI, because SELDOM can produce outputs for a wide variety of applications.

SDI and current awareness have received considerable emphasis in the literature by those providing search services over a spectrum of scientifictechnical tape services. Since MARC II has also elicited a tremendous response, especially from Kenneth Bierman of the Oklahoma Department of Libraries, these utilities do not merit additional treatment in this paper. SELDOM, however, is unique in that it is the only MARC-based SDI system capable of searches using six coordinated entry points, linear matching, truncation, weighting, and output options.

From the point of selection, MARC has great appeal. Since the majority of the University's acquisitions (i.e. almost 80\%) are English-language monographs, faculty and staff who have the responsibility for book selection would benefit from regular alerting services based on their areas of interest. Apart from receiving verified bibliographic information, the participants benefit from the timeliness of the records. At the same time, selection costs per record will be brought down significantly, especially now that this selection process becomes tied in to TESA-1, the Library's automated MARC-based acquisitions and cataloguing system. It has been suggested that selection and ordering could be done for the cost of selection alone. The only problem areas envisaged are the lack of Canadian imprints, and the lack of other non-English monographs, such as French, German, 
Spanish and Portugese. A partial solution to this problem may take the form of a Canadian MARC Project. A more complete solution is on its way, since MARC coverage for other languages is anticipated by the beginning of 1972 .

Collection rationalization, an area receiving considerable attention along regional and national lines, can also benefit from SELDOM. Devising divisions of responsibility in the acquisition of library materials will enable libraries to acquire, organize, store, and make available to the public, comprehensive monographic collections.

MARC deselection, where practised by subscribers, is being pursued mainly along the lines of time decay. The University of Chicago (21) has so far exhibited the only deselection algorithm employing a subject and intellectual level approach, in addition to date. They eliminate records from their file if they fall outside of their collection policy by using classification numbers. The OTS will be able to perform the same function, but much more rigorously, since its deselection criteria can consist of six elements. In this way, file size can be kept to a reasonable level, and update and storage charges will not be so high.

Internal library data and information services will be along the lines of SDI, current awareness, demand bibliographies, and management statistics. These in-house utilities, which are already being obtained, have been very useful. The Reference Department, for instance, receives a bibliography each week of MARC II reference sources. Another profile for one of the catalogers is monitoring the publications of the modern day novelists and poets.

\section{OUTLOOK}

SELDOM has been operational for only several months. While it has tremendous potential in the library field, and although immediate interest has been keen, the system will have to undergo considerable acceptance testing. Attention will have to be given to costs and to the user and his evaluation of the service. How SELDOM fits into a library's patron or reference services will be especially important, since the system will be integrated into a library's current accessions program and also the card catalog service.

\section{ACKNOWLEDGMENTS}

Major credit for the existence of the SELDOM Project is due to the systems analysts and programmers at the National Research Council of Canada, Messrs. P. H. Wolters, R. A. Green, J. Heilik, Miss R. Smith; and to Dr. J. E. Brown, National Science Librarian.

\section{REFERENCES}

1. Personal Communication with Henriette Avram, MARC Development Office, Library of Congress, Washington, D. C. 
2. Bierman, K. J.: "SDI Service," JOLA-Technical Communications, 1 (October 1970), 3.

3. Bierman, K. J.; Blue, Betty J.: "A MARC-Based SDI Service," Journal of Library Automation, 3 (December 1970), 304-319.

4. Bierman, K. J.: "An Operating MARC-Based SDI System: Some Preliminary Services and User Reactions," Proceedings of American Society for Information Science, 7 (1970), 87-90.

5. Bierman, K. J.: Statements of Progress of Cooperative SDI Project. In Oklahoma Department of Libraries: Automation Newsletter, 2 (February 1970), 3-4; 2 (June-August 1970); 2 (September 1970); 16, 25-26; 2 (December 1970), 34-35; 3 (February 1971), 1-3.

6. Studer, William J.: Computer-Based Selective Dissemination of Information (SDI) Service for Faculty Using Library of Congress MachineReadable Catalog (MARC) Records. (Ph.D. Dissertation, Graduate Library School, Indiana University, September, 1968).

7. Studer, William J.: "Book-Oriented SDI Service Provided for 40 Faculty." In Avram, Henriette: The MARC Pilot Project, Final Report (Washington, D. C.: Library of Congress, 1968) p. 179-183. Also in Random Bits, 3:3 (November 1967), 1-4; 3:4 (December 1967), 1-4, 6.

8. Avram, Henriette: "MARC Program Research and Development: A Progress Report," Journal of Library Automation, 2 (December 1969), 257-265.

9. Atherton, Pauline: "LC/MARC on MOLDS; An Experiment in Computer-Based, Interactive Bibliographic Storage, Search, Retrieval, and Processing," Journal of Library Automation, 3 (June 1970), 142-165.

10. Atherton, Pauline; Wyman, John: "Searching MARC Tapes with IBM/ Document Processing System," Proceedings of American Society for Information Science, 6 (1969), 83-88.

11. Atherton, Pauline; Tessier, Judith: "Teaching with MARC Tapes," Journal of Library Automation, 3 (March 1970), 24-35.

12. Hudson, Judith A.: "Searching MARC/DPS Records for Area Studies: Comparative Results Using Keywords, LC and DC Class Numbers," Library Resources and Technical Services, 14 (Fall 1970), 530-545.

13. Martin, Dohn H.: "MARC Tape as a Selection Tool in the Medical Library," Special Libraries, (April 1970), 190-193.

14. Veenstra, J. G.: "University of Florida." In Avram, Henriette D.: The MARC Pilot Project, Final Report (Washington, D.C.: Library of Congress, 1968), pp. 137-140.

15. Weisbrod, D. L.: "Yale University." In Avram, Henriette D.: The MARC Pilot Project, Final Report (Washington, D.C.: Library of Congress, 1968), pp. 167-173.

16. Palmer, Foster M.: "Harvard University Library." In Avram, Henriette D.: The MARC Pilot Project, Final Report (Washington, D.C.: Library of Congress, 1968), pp. 103-111. 
17. Tell, B. V.; Larsson, R.; Lindh, R.: "Information Retrieval With the ABACUS Program: an Experiment in Compatibility," Proceedings of a Symposium on Handling of Nuclear Information (Vienna: 16-20 February, 1970), p. 184.

18. Heaps, D.; Shapiro, V.; Walker, D.; Appleyard, F.: "Search Program for MARC Tapes at the University of Alberta," Proceedings of the Annual Meeting of the Western Canada Chapter of the American Society for Information Science, (Vancouver: September 14, 15, 1970), 83-94.

19. Ayres, F. H.: "Making the Most of MARC; its Use for Selection, Acquisitions, and Cataloguing," Program, 3 (April 1969), 30-37.

20. Dieneman, W.: "MARC Tapes in Trinity College Library," Program, 4 (April 1970), 70-75.

21. "MARC II and its Importance for Law Libraries," Law Library Journal, 63 (November 1970), 505-525.

22. Wolters, Peter H.; Brown, Jack E.: “CAN/SDI System: User Reaction to a Computerized Information Retrieval System for Canadian Scientists and Technologists," Canadian Library Journal, 28 (January, February 1971), 20-23.

23. Mauerhoff, Georg R.: "NSL Profiling and Search Editing," Proceedings of the Annual Meeting of the Western Canada Chapter of the American Society for Information Science, (Vancouver: September 14, 15, 1970), 32-53. 